\title{
PRIMARY LARYNGEAL TUBERCULOSIS MIMICKING AS SUPRAGLOTTIC MALIGNANCY
}

\author{
Abhilash Shambulinge Gowdaㄹ, Prakash Tumkur Kumaraswamy², Sundara Raju Huchaiah ${ }^{3}$, Rajeshwari Govinda Swamy4, \\ Kamal Pandyan 5 \\ ${ }^{1}$ ENT Surgeon, Department of Otorhinolaryngology, All India Institute of Speech and Hearing, Manasagangothri, Mysuru. \\ ${ }^{2}$ Reader, Department of Otorhinolaryngology, All India Institute of Speech and Hearing, Manasagangothri, Mysuru. \\ 3 Professor, Department of Otorhinolaryngology, All India Institute of Speech and Hearing, Manasagangothri, Mysuru. \\ 4 Professor and HOD, Department of Otorhinolaryngology, All India Institute of Speech and Hearing, Manasagangothri, Mysuru. \\ ${ }^{5}$ ENT Surgeon, Department of Otorhinolaryngology, All India Institute of Speech and Hearing, Manasagangothri, Mysuru.
}

\section{ABSTRACT}

\section{BACKGROUND}

Primary involvement of larynx is rare, usually it occurs as secondary to pulmonary tuberculosis. The incidence of laryngeal tuberculosis is drastically reduced due to improvement in public health care and anti-tubercular treatment. On laryngoscopy, it often mimicks supraglottic malignancy, so it is better to take a biopsy and to do histopathological examination to confirm the diagnosis.

\section{MATERIALS AND METHODS}

A 31-year-old female patient presented to our OPD with a history of hoarseness of voice and odynophagia since 6 months. General physical examination is normal. Indirect laryngoscopic examination revealed an ulcerative lesion over the epiglottis, arytenoids and interarytenoid area. Oedema and hyperaemia are noticed over the supraglottic larynx. Vocal cords are mobile on both the sides. Direct laryngoscopy and biopsy is taken to confirm the diagnosis.

\section{RESULTS}

The histopathological examination revealed hyperplastic squamous epithelium with epithelioid cells and Langhans giant cells. The patient is started on anti-tubercular treatment.

\section{CONCLUSION}

After 6 months of treatment, patient became completely asymptomatic and the lesions disappeared. Tuberculosis of larynx should be suspected in cases presenting with hoarseness of voice and odynophagia mimicking a 'laryngopharyngeal malignancy.'

\section{KEYWORDS}

Histopathology, Tuberculosis, Malignancy.

HOW TO CITE THIS ARTICLE: Gowda AS, Kumaraswamy PT, Huchaiah SR, et al. Primary laryngeal tuberculosis mimicking as supraglottic malignancy. J. Evolution Med. Dent. Sci. 2017;6(20):1647-1649, DOI: 10.14260/Jemds/2017/361

\section{BACKGROUND}

Primary laryngeal tuberculosis is rare, usually it is associated with pulmonary tuberculosis.[1,2] It is caused by the acid-fast bacilli, Mycobacterium tuberculosis. It occurs generally in adults without BCG vaccination or in cases of the acquired immunodeficiency syndrome. In India, tuberculosis is an important disease of public health importance. Recent studies have shown decline in the prevalence and mortality rate due to tuberculosis with the improvement in the health care and anti-tubercular treatment.[3] However, in recent years the diagnosis as well as complete cure of the disease has become difficult due to epidemic spread of HIV, illicit drug use and the emergence of multi-drug resistance. Currently, incidence of primary laryngeal tuberculosis is estimated to be less than $1 \%$ of all TB cases.[4]

Financial or Other, Competing Interest: None.

Submission 01-02-2017, Peer Review 25-02-2017,

Acceptance 03-03-2017, Published 09-03-2017.

Corresponding Author:

Dr. Abhilash Shambulinge Gowda,

D. No. 870,

$24^{\text {th }}$ Cross,

$4^{\text {th }}$ Main, Vidyaranyapuram,

Mysuru-570008.

E-mail: dr.abhilashs@yahoo.in

DOI: $10.14260 /$ jemds $/ 2017 / 361$

\section{(c) (1) $(9)$}

\section{Case Report}

A 31-year-old female patient presented in the outpatient Department of ENT, and Head and Neck Surgery with the chief complaints of hoarseness of voice and pain during swallowing since 6 months' duration and history of weight loss and loss of appetite present. There was no associated history of dyspnoea, dysphagia, fever, cough, chest pain, haemoptysis and stridor. Her prior medical history was unremarkable. There is no history of alcohol abuse or smoking.

On general examination, the patient's general condition was good with no palpable cervical lymph nodes. Clinical systemic examination did not reveal any abnormality in the respiratory, cardiovascular, gastrointestinal and central nervous system. On ENT examination, indirect laryngoscopic examination revealed an ulcerative lesion over the epiglottis, arytenoids and interarytenoid area. Oedema and hyperaemia noticed over the supraglottic larynx. Vocal cords are mobile on both the sides. Examination of the ears, nose and Paranasal Sinus (PNS) did not reveal any abnormality. On routine examination of blood, haemoglobin estimation was $10.0 \mathrm{~g} / \mathrm{dL}$, erythrocyte sedimentation rate of $15 \mathrm{~mm}$ was seen at the end of first hour. Total leucocyte count $5.3 \times 10^{3}$ cells per cubic mm. Liver and renal function tests are normal. Chest X-ray (PA view) showed normal lung fields. Upper GI endoscopy showed ulcerative lesion in the epiglottis, arytenoids and interarytenoid area. Epiglottic and arytenoids 
are oedematous and congested. Both the vocal cords are mobile [Figure 1,2].


Figure 1 and 2. Endoscopic Picture of the Larynx

Serological test for human immunodeficiency virus and hepatitis $\mathrm{B}$ virus are non-reactive. Abdominal ultrasonography is done to rule out abdominal tuberculosis. Direct laryngoscopic examination was done under general anaesthesia and biopsy was taken and sent for histopathological examination. The histopathological examination showed hyperplastic squamous epithelium with intracellular oedema, exocytosis and focal ulceration. Subepithelium shows dense infiltration of inflammatory cells consisting of neutrophils, lymphocytes, plasma cells and eosinophils admixed with epithelioid granuloma and Langhans giant cells [Figure 3]. Ziehl-Neelsen staining on the tissue section showed the presence of scanty acid fast bacilli. Sputum AFB was negative. The patient was treated with antitubercular drugs for six months.

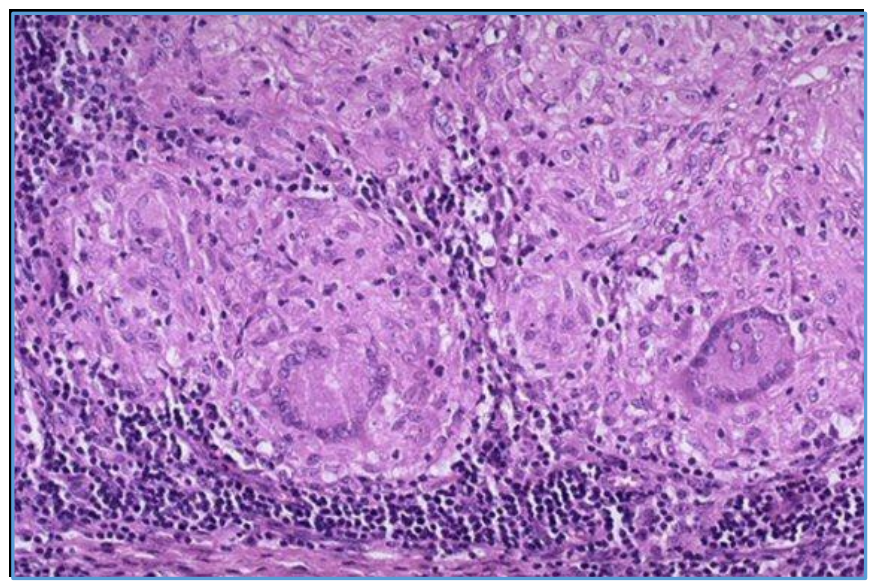

\section{Figure 3. Histopathological Picture of Laryngeal Tuberculosis}

\section{DISCUSSION}

Laryngeal tuberculosis tends to mimic laryngeal cancer and its laryngoscopic appearance often stimulates malignancy. Extrapulmonary $\mathrm{TB}$ in the head and neck region most frequently occurs in the cervical lymph nodes (> 90\%) followed by the larynx. Involvement of the pharynx, thyroid, temporal bone, sinonasal cavity, eye and skull base are even less frequently observed.[5,6] In the past, very few cases of isolated laryngeal tuberculosis have been reported. Laryngeal tuberculosis may present in varying forms, from erythematous lesion to ulceration and growth resembling carcinoma. ${ }^{[7]}$ Shin et al[8] described four different types of laryngeal tuberculosis namely ulcerative (40.9\%), nonspecific $(27.3 \%)$, polypoidal $(22.7 \%)$ and ulcero-fungating growth (9.1\%). Usually, the larynx is infected either by direct spread from the lungs or by haematogenous spread from sites other than the lungs. In the present situation, the otorhinolaryngologist faces a great difficulty to differentiate between laryngeal tuberculosis, chronic laryngitis and laryngeal malignancy. So complete work for malignancy has to be carried out before diagnosing as laryngeal tuberculosis without associated carcinoma. Odynophagia is described as an important discriminating symptom, since it is considered rare in laryngeal malignancy. Yet, from experience we know that many of the patients suffering from supraglottic malignancy present to us with a history of odynophagia.[9] Laryngeal tuberculosis occurs mostly in the middle age group with a history of progressive hoarseness and odynophagia; some factors have been found to occur in these patients that include the absence of BCG vaccination and presence of malnutrition, acquired immunodeficiency syndrome, immunosuppression, promiscuity and tobacco use. In the earlier days the most common site of laryngeal tuberculosis is posterior part of larynx, particularly in bedridden patients and in whom sputum got collected in the interarytenoid region. Fernandes et al[10] reports the most common part to be involved is the vocal cord (50\%-70\%) and least affected is the epiglottis. In this case the involved site is the epiglottis, arytenoids and interarytenoid area and the patient gives the history of progressive hoarseness and odynophagia of 6 months' duration along with the history of weight loss and loss of appetite; investigation showed normal chest radiograph and negative sputum for acid bacilli in $\mathrm{ZN}$ staining; this led us to suspect supraglottic malignancy but histopathological findings showed tubercular granuloma and the symptoms subsided with anti-tubercular drugs, so laryngeal malignancy is ruled out. Patients presenting with hoarseness of voice without any pulmonary symptoms in endemic regions, laryngeal tuberculosis should be considered in the differential diagnosis. If the patient is not treated early laryngeal TB can result in subglottic stenosis, muscular involvement and vocal cord paralysis when the cricoarytenoid joint or recurrent laryngeal nerves are invaded.

\section{CONCLUSION}

The patient was treated with anti-tubercular drugs for 6 months and called for followup. The symptoms subsided and there is no evidence of any lesions of laryngeal tuberculosis. In any laryngeal disease, laryngeal tuberculosis is considered as one of the differential diagnosis, especially in case of laryngeal malignancy who presents with the history of hoarseness of voice and odynophagia. The only confirmatory diagnosis is by histopathological examination when the routine investigations for tuberculosis are negative.

\section{REFERENCES}

[1] Baxi S, Jha S. Primary laryngeal tuberculosis--a rare entity. J Indian Med Assoc 2010;108(3):178-9.

[2] Edizer DT, Karaman E, Mercan H, et al. Primary tuberculosis involving epiglottis: a rare case report. Dysphagia 2010;25(3):258-60.

[3] Sachdeva KS, Kumar A, Dewan P. New vision for Revised National Tuberculosis Control Programme (RNTCP): Universal access - reaching the un-reached. Indian J Med Res 2012;135(5):690-4. 
[4] Egeli E, Oghan F, Alper M. Epiglottic tuberculosis in a patient treated with steroids for Addison's disease. Tohoku J Exp Med 2003;201(2):119-25.

[5] Moon WK, Han MH, Chang $\mathrm{KH}$, et al. CT and MR imaging of head and neck tuberculosis. Radiographics 1997;17(2):391-402.

[6] Nalini B, Vinayak S. Tuberculosis in ear, nose and throat practice: its presentation and diagnosis. Am J Otolaryngol 2006;27(1):39-45.

[7] Lindell MM, Jing BS, Wallace S. Laryngeal tuberculosis. AJR Am J Roentgenol 1977;129(4):677-80.
[8] Shin JE, Nam SY, Yoo SJ, et al. Changing trends in clinical manifestation of laryngeal tuberculosis. Laryngoscope 2000;110(11):1950-3.

[9] Hunter AM, Millar JW, Wightman AJ, et al. The changing pattern of laryngeal tuberculosis. Journal of Laryngology and Otology 1981;95(4):393-8.

[10] Fernandes L, Mesqnita A. Stridor presentation in laryngeal tuberculosis. Indian Journal of Tuberculosis 1997:44(2):93-4. 